\title{
An Integral Type Extrusion Die for Semi-Hollow Aluminum Alloy Profile
}

\author{
Rurong Deng ${ }^{1, a}$,Xuemei Huang ${ }^{2, b}$ \\ ${ }^{1}$ Guangzhou Vocational College of Science and Technology, Guangzhou, 510550, China \\ ${ }^{2}$ Guangzhou Vocational College of Science and Technology, Guangzhou, 510550, China

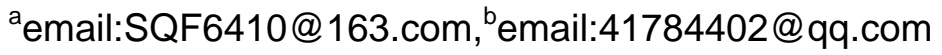

\begin{abstract}
Keywords: aluminum alloy,extrusion die,suspending,the feeder ring,open.
Abstract: The concept of semi-hollow profile was introduced.the characteristics of two kinds of dies with a penetrating plane and a cover were analyzed.through the real examples from practice,a design of integral type extrusion die for semi-hollow aluminum alloy profiles was introduced.the advantages and applicability of this structure were analyzed.and a detailed analysis of the key points of the design for the structure was made.the determination of each parameter was introduced.it is important to design an open structure, which is easy to process and maintain.objective to promote the technology and the die structure to the counterparts,to provide reliable and valid reference.
\end{abstract}

\section{Introduction}

Traditional aluminum profile extrusion die structure have the forms of hollow die and solid die,respectively, for the hollow section of profile and solid, but in the types and specifications of different aluminum products, and a is the industry known for "semi hollow profiles, is of great common.But in the types and specifications of different aluminum products, and one known as for "semi-hollow profile" in industry is also very common.and the definition of this type of profile is the ratio of the tongue to the $\mathrm{R}$, and the experience of $\mathrm{R}$ is shown in Table 1.

Table1: the figure of $\mathrm{W}$ and $\mathrm{Rmax}$

\begin{tabular}{c|c}
\hline $\mathrm{W}(\mathrm{mm})$ & $\mathrm{R} \max$ \\
\hline $1.0 \sim 1.5$ & 2 \\
\hline $1.6 \sim 3.1$ & 3 \\
\hline $3.2 \sim 6.3$ & 4 \\
\hline $6.4 \sim 12.6$ & 5 \\
\hline $12.7-$ & 6 \\
\hline
\end{tabular}

In table $1, \mathrm{~W}$ is the width of the profile, and Rmax is the maximum allowable value of ratio to the tongue.

In the traditional extrusion die design, for a certain opening width (W) of the profile, its ratio of tongue $\mathrm{R}$ is not beyond the provisions value specified in the table 1 . When the ratio $\mathrm{R}$ is more than the Rmax, we can determine the profile as "semi- hollow".And when the ratio of tongue is more than 10, the traditional and conventional structure of solid die can not be used.Because of this kind of situation, such as the use of conventional solid die structure, the die will appear obvious lack of strength, easy to cause the collapse of the die and broken.At present, the die structure of the "semi-hollow" profile mainly has the form of hollow die with penetrating plate and of hollow die with a cover. the form of hollow die with penetrating plate has a advantage of good strength, but But it is easy to produce the drawing and the phenomenon of the reinforcing bar in the touch of penetrating.this can not be applied to the profiles of the special requirements of the assembly requirements or of the special requirements on the surface quality of the profiles on the width of the opening.At the same time, for those profiles with a smaller opening, designed as a hollow die, due to the mandrel is too small,the mandrel will exist easily risk factors such as easy to break or deform. And using the structure of hollow die with a cover,the cantilever is covered and protected by the male die gave a certain stress gap like a cover.It is avoided that the cantilever is directly under the metal extrusion pressure, so as to improve the stress state of the cantilever, improve the strength of 
the mold.However, this structure can not solve the uneven or speed of the cantilever on both sides of the metal flow due to the uneven or speed of the additional tensile stress, which leads to the side of the cantilever and break off.however this structure can not solve the additional tensile stress from the uneven or speed difference in metal flow on both sides of the cantilever which it will take the tongue of cantilever to break off.especially for these profiles,their opening width of less than 10mm and their tongue ratio $\mathrm{R}$ is greater than 10 ,and these profiles are asymmetric also.as shown in Figure 1.

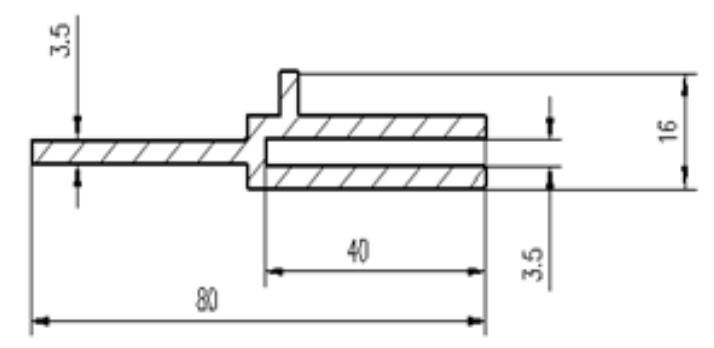

Fig.1 the signal of non-symmetrical profile

In order to solve such problems, the domestic and foreign technical personnel conducted a wide range of research.in this paper,through practical examples, a integral type extrusion die structure was introduced,it can effectively solve the problems for peer reference.

\section{Die Structure Design Principle}

The structure called "integral type", is that the cantilever bottom (non-open position) like a suspension bridge under the male die.this will change the force structure and state of cantilever from a cantilever beam which is equivalent to one end fixed to a simply supported beam with two ends fixed.this greatly increase the strength of the die.as shown in figure 2.

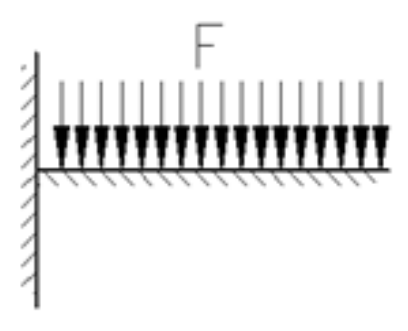

(a)

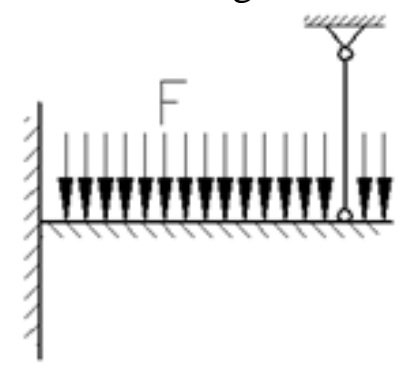

(b)

Fig.2 the signal of cantilever force

In the figure2,(a ) is a cantilever beam one end fixed;(b) is simply supported beam with two ends fixed.

\section{The Design of Die Structure}

As shown in figure 3. Set the porthole bridge (suspension bridge) in the vertical direction of the cantilever.the width of bridge should not be too large,otherwise,the supply of metal into the die hole under the bridge will be difficult.if the tongue is too long.the porthole bridge can be designed for 2 or more .the principle is that the length of tongue to sustain the positive pressure directly during the 


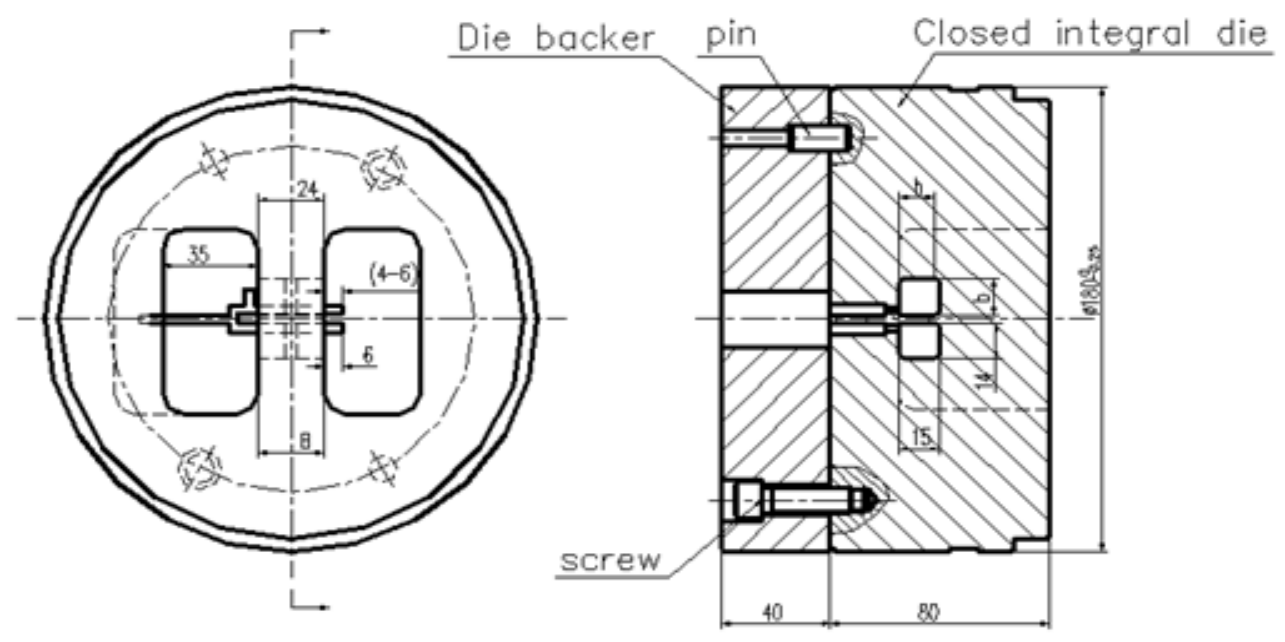

Fig.3 the signal of closed die structure

metal extrusion is not more than $25 \mathrm{~mm}$. (or the distance between two adjacent bridge).the difference between the area of the porthole must be considered in the $12 \%$ range.the design points are as follows:

(1) the width of bridge $B=(16 \sim 26) \mathrm{mm}$.

(2) The maximum distance between the edge of porthole bridge and the bottom end of the cantilever is not too long $L \max =(4 \sim 6) \mathrm{mm}$.

(3) the design of guide flow hole under the bridge is shown in figure 4.among them,the height $h=(15 \sim 20) \mathrm{mm}$; the width $b=(8 \sim 14) \mathrm{mm}$.

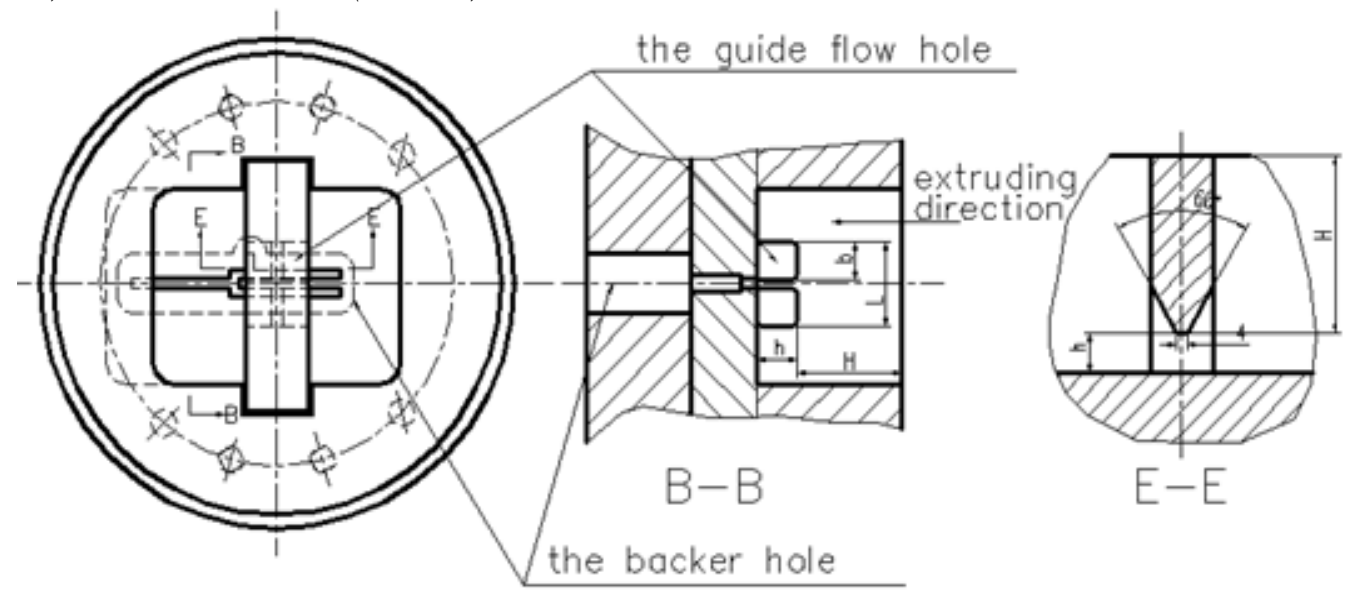

Fig.4 the signal of design for the guide holes

(4) the strength check to the porthole bridge as follows:

$H \geq \sqrt{\frac{P}{2[\sigma]_{b}}} \bullet L$

Introduction as follows:

(1) $\mathrm{H}$-the minimum height of dangerous section of the die.

(2) $L$-the distance between two dangerous section of porthole bridge.

(3) $P$-pressure ratio of extrusion container

(4) $[\sigma]_{b}$-the allowable bending stress (MPa) of the material,it is taken from $1150 \mathrm{MPa}$ by H13

(5)the ratio of feeder flow $K=(0.3 \sim 0.4) \lambda(\lambda$-extrusion ratio) 
(6) the bearing belt is chosen according to a conventional principle

Those design,it makes the cantilever,die hole and the bridge of porthole become a closed whole.from the strength of die,metal flow and forming,it has the advantages of the die with a cover,to improve the stress state of cantilever,with the characteristics of the hollow die with a penetrating plane,the metal forming easier,and the advantages of no wire drawing and initial also.But the biggest shortcoming is that in practice the die processing and the maintenance difficulty is big.Based on this feature,after a long period of exploration,the closed structure was improved to an open structure.as shown in figure 5.
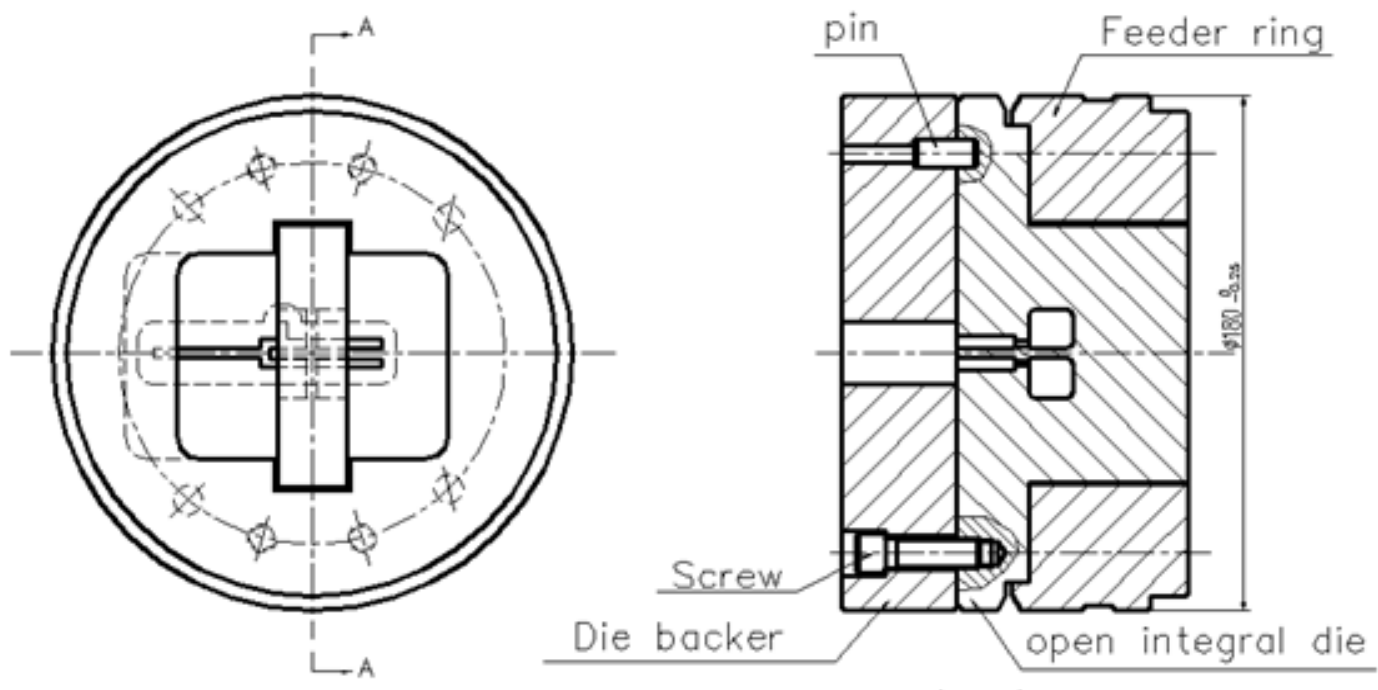

Fig. 5 the signal of open die structure

It is that only the cantilever and the porthole bridge were designed as a whole,the cantilever was

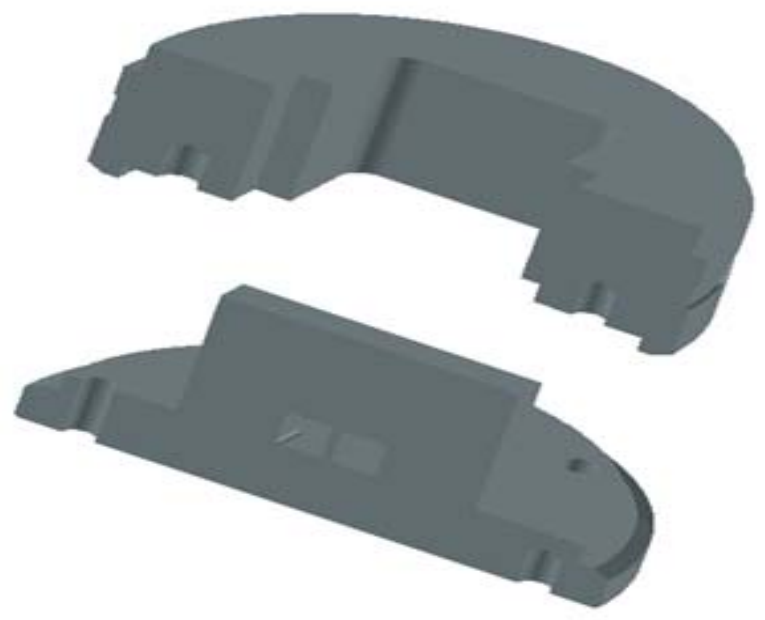

Fig.6 the signal of the integral and the feeder ring

hanged under the bridge,and the metal feed into the die through a feeder ring.this makes the die processing and maintenance become very convenient,and the form of integral die and the feeder ring were shown in figure 6 .

The size fit relationship of the feeder ring and the porthole bridge was shown in figure 7. 


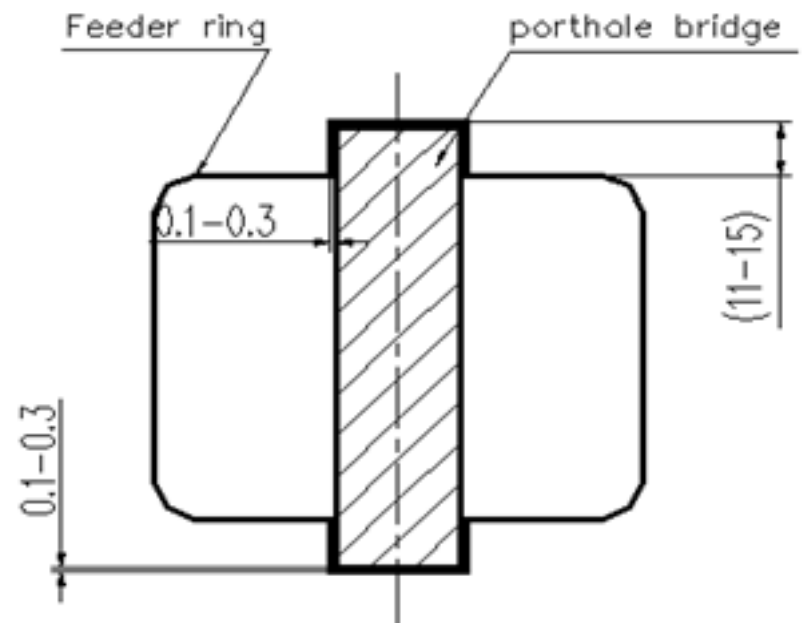

Fig.7 the diagram of dimension coordinate for feeder hole and bridge

\section{Conclusions}

The integral extrusion die structure has been applied in practice. The practice shows that the effect is good.For the semi-hollow profiles,with a big tongue ratio and small open width or with a simple hollow part and bigger tongue ratio.in particular,when the open width is less than $10 \mathrm{~mm}$ and its tongue ratio $\mathrm{R}$ is more than 6 .it will be more effective,more applicable and targeted.If combined the two die structure of the hollow extrusion die with a penetrating plane and the extrusion die with a cover.the solution methods and means will be more perfect and complete to the die problems of the semi-hollow profiles.the key to the integral extrusion die is to design an open die structure.the main parameters include the width of bridge,the determination for location of porthole bridge,the design of guide flow hole and determination of the ratio of feeder flow.etc.Therefore,it can be seen that the reasonable die structure and parameters can be in the premise of ensuring the strength of the die, which is conducive to the formation of metal,but also easy to die processing and maintenance, And achieve the purpose to ensure the quality of products and improve the die life.

\section{References}

[1]Ru-rong Deng, Lei Zeng. The design of flow-guided die in large solid section [J],Light alloy fabrication technology, 2014(11): 29 31 In Chinese

[2]Jian-xin Xie , Jing-an Liu.Metal extrusion theory and technology[M].Metallurgical Industry Press, Beijing, 2001: 28〜31，68～69 In Chinese

[3]Zu-tang Wang,Xin-quan Zhang. Research on the design technology of the flow guided die for aluminum profile extrusion die[J],Light alloy fabrication technology,1992(01): 38 42In Chinese

[4]Jing-an Liu. Aluminum alloy extrusion die design,use and maintenance.[M],Metallurgical Industry Press, Beijing,1999:159 167 In Chinese

[5]Ru-rong Deng.To determine the key parameters of aluminum extrusion die design by shunt[J],Light alloy fabrication technology,2002,30(2) : 23 24 In Chinese

[6]Guang Wang,Jian Liu.Technology study of coarse grain ring of 2024 aluminum alloy extrusion bar[J],Light alloy fabrication technology,2013(04): 36 40 In Chinese 
[7]Ke-Wei Zhang,Lei Zhang.Effect of pre-stretching on microstructure and mechanical properties of 2A12 aluminum alloy bar[J],Light alloy fabrication technology,2013(11): 37 40 In Chinese

[8]Guang-Lei Lin.Study on the production process of 7A04-T6 aluminum alloy rod[J],Light alloy fabrication technology,2007(11): 33 36 In Chinese

[9]Hong-Mei Zhang,Yu-Jie Su.Research about big grain 6061-T6 aluminum alloy rod centre[J],Light alloy fabrication technology,2005(08): 34 36 In Chinese

[10]Zhen-Hua Cao,Wei Rong.Research on the problem of coarse grain ring on extrusion bar of 6082 aluminum alloy[J],Heat treatment technology and equipment,2014(10):21 23 In Chinese

[11]Feng Wen,Tie Li.Method of eliminating coarse grain ring of 2A02 aluminum alloy[J],Light alloy fabrication technology,2003(03): 33 36 In Chinese

[12]Lei Guo,Dan-Qing Yi.Effect of extrusion ratio on microstructure and electrical properties of AA8030 aluminum alloy rod[J],The Chinese Journal of Nonferrous Metals,2013(08): 22 29 In Chinese

[13]Yi-Lei Wang,Wang-Yuan Tian.Coarse grain ring controlling way of 6A02 aluminum alloy extrusion bar In Chinese

[14]Xiu-feng Wang. Discussion about how to overcome defects of aluminum profiles as designing dies for extruding aluminum alloy[J],Light alloy fabrication technology,2006(01): 35 37 In Chinese

[15]Xue-mei Sun,Guo-qun.Fake porthole extrusion die structure design and strength analysis for cantilever aluminum alloy profiles[J],Journal of mechanical engineering,2013(12): 39 44 In Chinese 